\title{
Size-dependent density of zirconia nanoparticles
}

\author{
Agnieszka Opalinska ${ }^{1}$, Iwona Malka*1, Wojciech Dzwolak ${ }^{1}$, Tadeusz Chudoba ${ }^{1}$, \\ Adam Presz ${ }^{1}$ and Witold Lojkowski ${ }^{1,2}$
}

\author{
Full Research Paper \\ Address: \\ ${ }^{1}$ Institute of High Pressure Physics, Polish Academy of Science, \\ Sokołowska 29/37, 01-142 Warsaw, Poland and ${ }^{2}$ Faculty of \\ Management, Białystok University of Technology, Wiejska 45A, \\ 15-351 Białystok, Poland \\ Email: \\ Iwona Malka* - iwona@unipress.waw.pl \\ * Corresponding author

\section{Keywords:} \\ density; hydrothermal synthesis; hydroxy groups; nanometrology; \\ nanopowders; zirconia
}

\author{
Beilstein J. Nanotechnol. 2015, 6, 27-35. \\ doi:10.3762/bjnano.6.4 \\ Received: 18 April 2014 \\ Accepted: 17 November 2014 \\ Published: 05 January 2015 \\ Associate Editor: R. Naaman \\ (C) 2015 Opalinska et al; licensee Beilstein-Institut. \\ License and terms: see end of document.
}

\begin{abstract}
The correlation between density and specific surface area of $\mathrm{ZrO}_{2}$ nanoparticles (NPs) was studied. The NPs were produced using a hydrothermal process involving microwave heating. The material was annealed at $1100{ }^{\circ} \mathrm{C}$ which resulted in an increase in the average grain size of the $\mathrm{ZrO}_{2} \mathrm{NPs}$ from 11 to $78 \mathrm{~nm}$ and a decrease in the specific surface area from 97 to $15 \mathrm{~m}^{2} / \mathrm{g}$. At the same time, the density increased from $5.22 \mathrm{~g} / \mathrm{m}^{3}$ to $5.87 \mathrm{~g} / \mathrm{m}^{3}$. This effect was interpreted to be the result of the presence of a hydroxide monolayer on the NP surface. A smaller $\mathrm{ZrO}_{2}$ grain size was correlated with a larger contribution of the low density surface layer to the average density. To prove the existence of such a layer, the material was synthesized using $50 \%$ heavy water. Fourier transform infrared spectroscopy (FTIR) permitted the identification of the -OD groups created during synthesis. It was found that the -OD groups persisted on the $\mathrm{ZrO}_{2}$ surface even after annealing at $1100{ }^{\circ} \mathrm{C}$. This hydroxide layer is responsible for the decrease in the average density of the NPs as their size decreases. This study of the correlation between particle size and density may be used to assess the quality of the NPs. In most cases, the technological aim is to avoid an amorphous layer and to obtain fully crystalline nanoparticles with the highest density possible. However, due to the effect of the surface layers, there is a maximum density which can be achieved for a given average NP diameter. The effect of the surface layer on the NP density becomes particularly evident for NPs smaller than $50 \mathrm{~nm}$, and thus, the density of nanoparticles is size dependent.
\end{abstract}

\section{Introduction}

Zirconium oxide $\left(\mathrm{ZrO}_{2}\right)$ has a wealth of potential applications in the fields of catalysis [1,2], restorative dentistry, high temperature ceramics $[3,4]$, polymer nanocomposites $[5,6]$ and sensors [7]. The characteristics of nanoscale $\mathrm{ZrO}_{2}$ (including the mechanical, electrical, chemical, as well as catalytic properties) differ from those of conventional micrometer-sized $\mathrm{ZrO}_{2}$. These differences are the result of the unusual properties which occur at the nanoscale and the surface phenomena [8-10]. 
Using nano- $\mathrm{ZrO}_{2}$ as a waveguide host matrix material for light and optical amplification is promising due to its very good chemical and photochemical stability [11-13], high refractive index, and good transparency from the visible to the NIR spectral range [14-16]. Nano- $\mathrm{ZrO}_{2}$ is an established, excellent host material for rare earth ions; for example, $\mathrm{ZrO}_{2}: \mathrm{Eu}^{3+}$ is used as a red luminophore $[17,18]$. When nano- $\mathrm{ZrO}_{2}$ is used as a luminescent material, the luminescence intensity increases with crystallite size [17].

The size and surface properties of NPs are also important for toxicology and health applications. The size of the NPs can influence their distribution in the human body and the mechanism of their penetration into the cells and tissues [19]. The chemical composition of the nanomaterial surface has a strong influence on its chemical interaction with tissue [20].

Microcrystalline $\mathrm{ZrO}_{2}$ has three polymorphs: monoclinic (m), tetragonal $(\mathrm{t})$, and cubic (c) phases. The monoclinic phase is thermodynamically stable up to $1100{ }^{\circ} \mathrm{C}$ and transforms to $\mathrm{t}-\mathrm{ZrO}_{2}$, which exists in the temperature range $1100-2370{ }^{\circ} \mathrm{C}$, while the cubic phase is found above $2370{ }^{\circ} \mathrm{C}$ [21]. However, for nanocrystalline powders, the tetragonal phase can be obtained directly during hydrothermal synthesis.

It was previously observed that density, specific surface area, and phase composition of nano- $\mathrm{ZrO}_{2}$ depends on the hydrothermal synthesis conditions. An increase of the synthesis temperature above $260^{\circ} \mathrm{C}$ leads to an increase in the nano- $\mathrm{ZrO}_{2}$ density. It should be noted that in this case the density was always less than that of bulk $\mathrm{ZrO}_{2}$ [22]. The improvement in the density was attributed to the higher crystallinity of the nanoparticles, that is, a smaller amount of amorphous hydroxides were present as the synthesis temperature was increased.

The presence of hydroxy groups on the nanoparticle surface may strongly influence many of their properties such as their chemical reactivity and hydrophilic properties. The hydroxy groups on the NP surface can also operate as effective adsorption sites for organic substances from the atmosphere [23]. Grave and colleagues attributed the increase of the nanopowder luminescence intensity with gain growth to the elimination of surface hydroxy $(-\mathrm{OH})$ groups by heat treatment [24].

The influence of $-\mathrm{OH}$ groups on various properties of nanooxides has been extensively examined [25-28]. Takeda reported that $-\mathrm{OH}$ groups on $\mathrm{SiO}_{2}$ surface can function as effective reactive sites [23]. The surface reactivity of oxide films depends on the number of surface $-\mathrm{OH}$ groups. Moreover, the $-\mathrm{OH}$ groups on the nanomaterial surface can influence the surface reactivity and wetting [26].

Since hydroxy groups greatly affect the properties of zirconia nanoparticles, detecting their surface concentration and optimizing the synthesis procedures to eliminate or reduce them is of significant technological interest. A number of methods have been developed to measure the hydroxy group site density as well as mechanisms of hydroxylation of nanopowder surfaces [27]. These methods include reaction with Grignard reagents, dehydration by heating, and FTIR spectroscopy. FTIR spectroscopy is a very sensitive and versatile method for the detection of hydroxy groups and it may be easily coupled to the task of chemical group characterization of the nanoparticle surface.

Most nanoparticle characterization methods are focused on the NP size distribution. However, the nanoparticle density measured using helium pycnometry provides valuable information about their phase composition, in the same way as density conveys information about the phase composition of bulk materials. The aim of this paper is to present a method for nanoparticle characterization that permits quality assessment based on density measurements, and also invokes a correction resulting from the surface contribution to the density. The novelty of our findings is a correlation between the density and the specific surface area. This interdependence can be used in nanometrology.

\section{Results and Discussion Phase composition and morphology of $\mathrm{ZrO}_{2}$ nanopowders}

The XRD patterns of $\mathrm{ZrO}_{2}$, which was synthesized at $5.5 \mathrm{MPa}$ for $20 \mathrm{~min}$ and annealed at 500, 700, 900 and $1100{ }^{\circ} \mathrm{C}$, are presented in Figure 1. It can be seen that powders synthesized with an annealing temperature above $700{ }^{\circ} \mathrm{C}$ contained only the monoclinic phase, which was in agreement with known data. Our observations were in agreement with [29-32] where nanocrystalline powders synthesized by hydrothermal techniques contained mainly mixed phases.

We examined the average grain size of the $\mathrm{ZrO}_{2}$ powders as a function of the annealing temperature (Figure 2). The grain size was evaluated by determining the specific surface area obtained from BET analysis and also from the Scherrer equation. Additionally, the average crystallite and grain size, as well as the phase content of the zirconia powders are given in Table 1. Annealing the powders at a temperature lower than $500{ }^{\circ} \mathrm{C}$ did not result in an increase in the crystallite size, where the crystallites remained approximately $11 \mathrm{~nm}$ in diameter. As the annealing temperature of the nano- $\mathrm{ZrO}_{2}$ was increased, the 


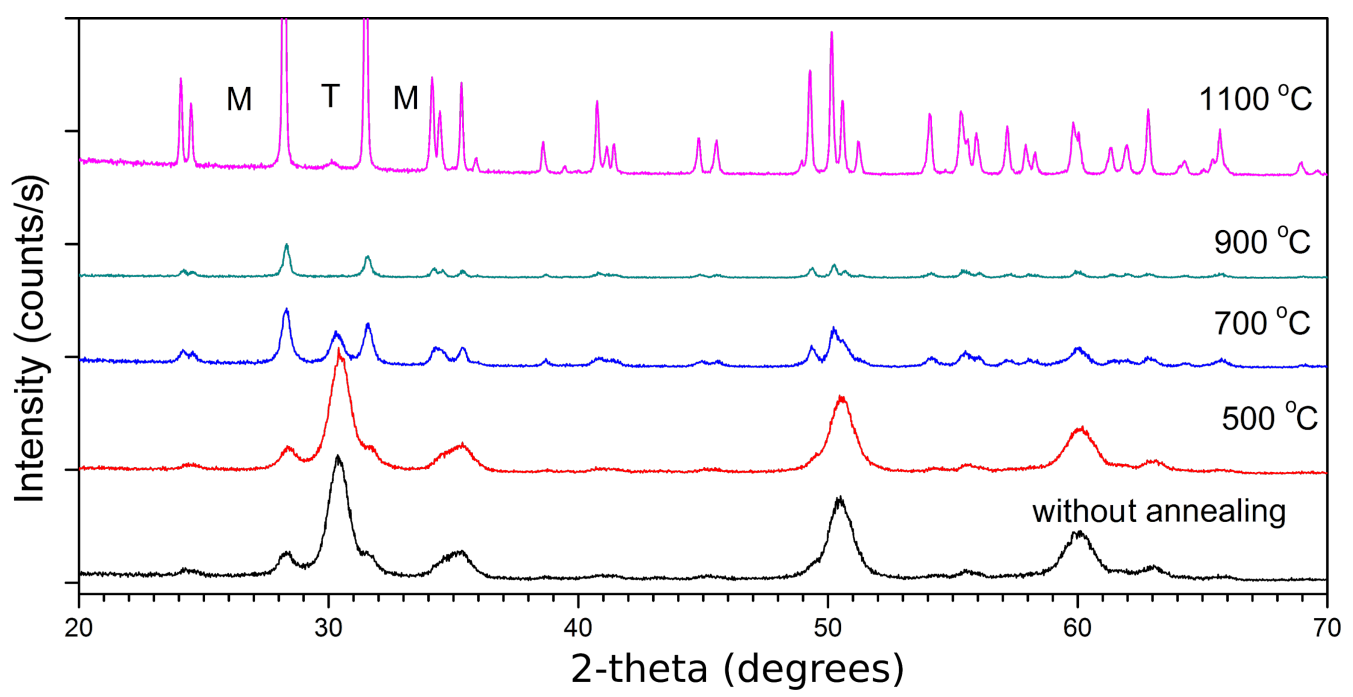

Figure 1: X-ray diffraction patterns of $\mathrm{ZrO}_{2}$ synthesized at $5.5 \mathrm{MPa}$ for 20 min and annealed in air for 30 min at the given temperatures. The diffraction peaks assigned to the tetragonal phase and the monoclinic phase are marked as $\mathrm{T}$ and $\mathrm{M}$, respectively.

average crystallite and grain size of the powder increased. The presence of agglomerates and particles almost 5 times larger than the nano- $\mathrm{ZrO}_{2}$ annealed at $500{ }^{\circ} \mathrm{C}$ was found. For powders annealed at $1100{ }^{\circ} \mathrm{C}$, the crystallite diameter increased even further to a diameter of $72 \mathrm{~nm}$ (according to the Scherrer equation).

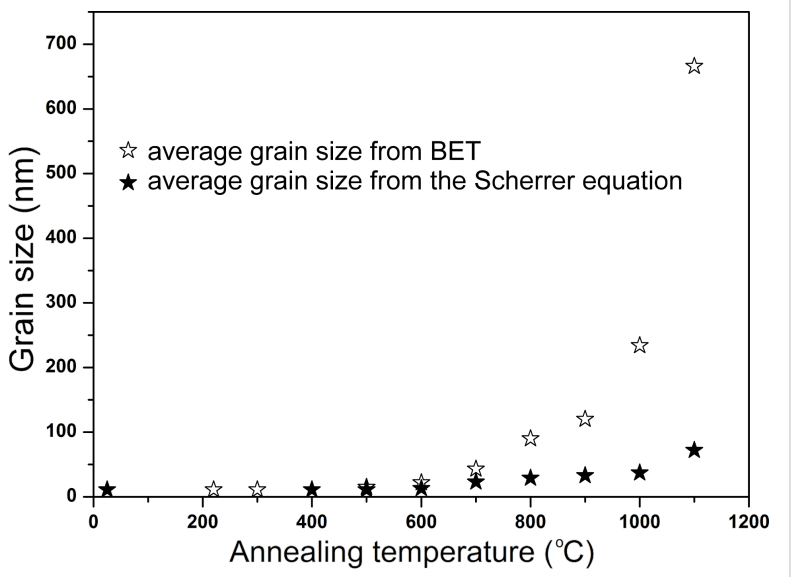

Figure 2: The average grain size of the $\mathrm{ZrO}_{2}$ powder as a function of the annealing temperature.

The increase in the $\mathrm{ZrO}_{2}$ grain size with increasing annealing temperature was also clearly visible in SEM images (Figure 3). The grains were predominately spherical and tended to form agglomerates (Figure 3C). The much higher apparent particle size is the result of particle sintering.

\section{Characterization of the $-\mathrm{OH} /-\mathrm{OD}$ groups}

The amount of $-\mathrm{OH} /-\mathrm{OD}$ groups on the nano- $\mathrm{ZrO}_{2}$ surface was assessed by FTIR measurements. The -OD spectral bands are present in all $\mathrm{ZrO}_{2}$ samples synthesized in the presence of $\mathrm{D}_{2} \mathrm{O}$ (Figure 4). Three major peaks are visible in the original absorption spectra at 2610,2548, and $2537 \mathrm{~cm}^{-1}$ (Figure 4A), although a resolution enhancement by displaying the second derivative reveals another minor band at $2529 \mathrm{~cm}^{-1}$ (Figure 4B). It is likely that the four bands correspond to four different populations of -OD groups and they are likely to reflect different surface sites where the -OD groups are attached. The -OD stretching band is in an otherwise "empty" spectral region, as illustrated by the corresponding spectrum of a $\mathrm{H}_{2} \mathrm{O}$-only preparation of $\mathrm{ZrO}_{2}$ (the dotted line in Figure 4C). The well-defined splitting of the -OD band into four separate peaks suggested a highly structured molecular environment of the hydroxide groups, with little hydrogen bonding. This result is opposed to the very broad and featureless -OD band typical for solvents (such as $\mathrm{D}_{2} \mathrm{O}$ ) or fast-interchanging hydrogen bonds. The top spectra in Figure 4A and Figure 4C (corresponding to the unheated $\mathrm{ZrO}_{2}$ sample) clearly indicate the presence of such a broad, featureless -OD band, which disappeared upon heating to $100-200{ }^{\circ} \mathrm{C}$. This band reflects molecular water adsorbed on the nanoparticle surface or between nanoparticles, and disappears upon drying of the nanopowder. The spectral contribution of these "low-order" -OD groups appears as the area below the three major peaks in Figure 4A. The subsequent spectra, recorded at increasing temperatures (Figure 4C), revealed that the well-ordered, surface -OD groups remained even at $1100{ }^{\circ} \mathrm{C}$ (Figure $4 \mathrm{C}$ and Figure 4A). A spectral band at 
Table 1: The average grain size, density and amount of monoclinic phase as a function of the annealing temperature of the nano- $\mathrm{ZrO}_{2}$ powders.

\begin{tabular}{lllll}
$\begin{array}{l}\text { Annealing } \\
\text { temperature }\left[{ }^{\circ} \mathrm{C}\right]\end{array}$ & $\begin{array}{l}\text { Average crystallite size from } \\
\text { the Scherrer equation }[\mathrm{nm}]\end{array}$ & $\begin{array}{l}\text { Average grain/agglomerate } \\
\text { size from BET [nm] }\end{array}$ & $\begin{array}{l}\text { Amount of monoclinic } \\
\text { phase [\%] }\end{array}$ & ${\text { Density }\left[\mathrm{g} / \mathrm{cm}^{3}\right]^{\mathrm{a}}}^{\text {Dhe }}$ \\
\hline no annealing & 11 & - & 21 & - \\
400 & 11 & 11 & 23 & $5.22 \pm 0.07$ \\
500 & 11 & 15 & 17 & $5.50 \pm 0.08$ \\
600 & 13 & 22 & 31 & $5.43 \pm 0.09$ \\
700 & 23 & 43 & 50 & $5.58 \pm 0.06$ \\
800 & 29 & 90 & 100 & $5.77 \pm 0.07$ \\
900 & 33 & 120 & 100 & $5.77 \pm 0.05$ \\
1000 & 37 & 234 & 100 & $5.72 \pm 0.01$ \\
1100 & 72 & 666 & 100 & $5.87 \pm 0.02$ \\
\hline
\end{tabular}

${ }^{\mathrm{a} S D}=0.05$

$1250 \mathrm{~cm}^{-1}$, characteristic of the molecular D-O-D deformation, was absent in the spectra of all $\mathrm{ZrO}_{2}$ samples. This indicates that the observed vibrations stem from -OD groups covalently bound to zirconia, rather than from trapped $\mathrm{D}_{2} \mathrm{O}$ molecules.
The stability of $-\mathrm{OH}$ groups on the surface of nano-oxides annealed under various temperatures has also been observed by other authors $[23,27]$. The decomposition of the $\mathrm{Zr}-\mathrm{OD} / \mathrm{OH}$ groups on the NP surface leads to formation of unsaturated
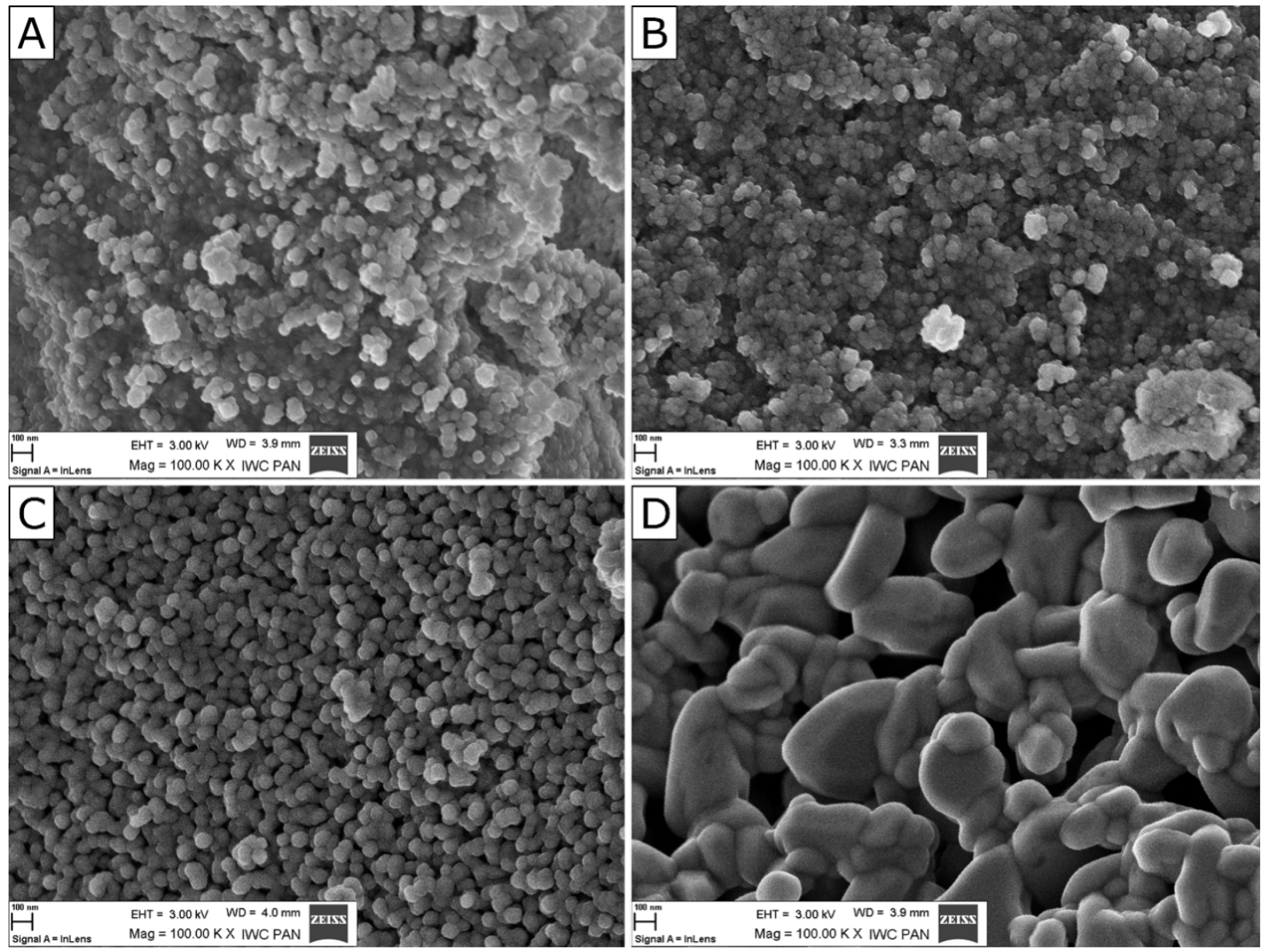

Figure 3: SEM images of four selected nano- $\mathrm{ZrO}_{2}$ samples: (A) no annealing, and after annealing at (B) $500{ }^{\circ} \mathrm{C},(\mathrm{C}) 800{ }^{\circ} \mathrm{C}$ and (D) $1100{ }^{\circ} \mathrm{C}$. 

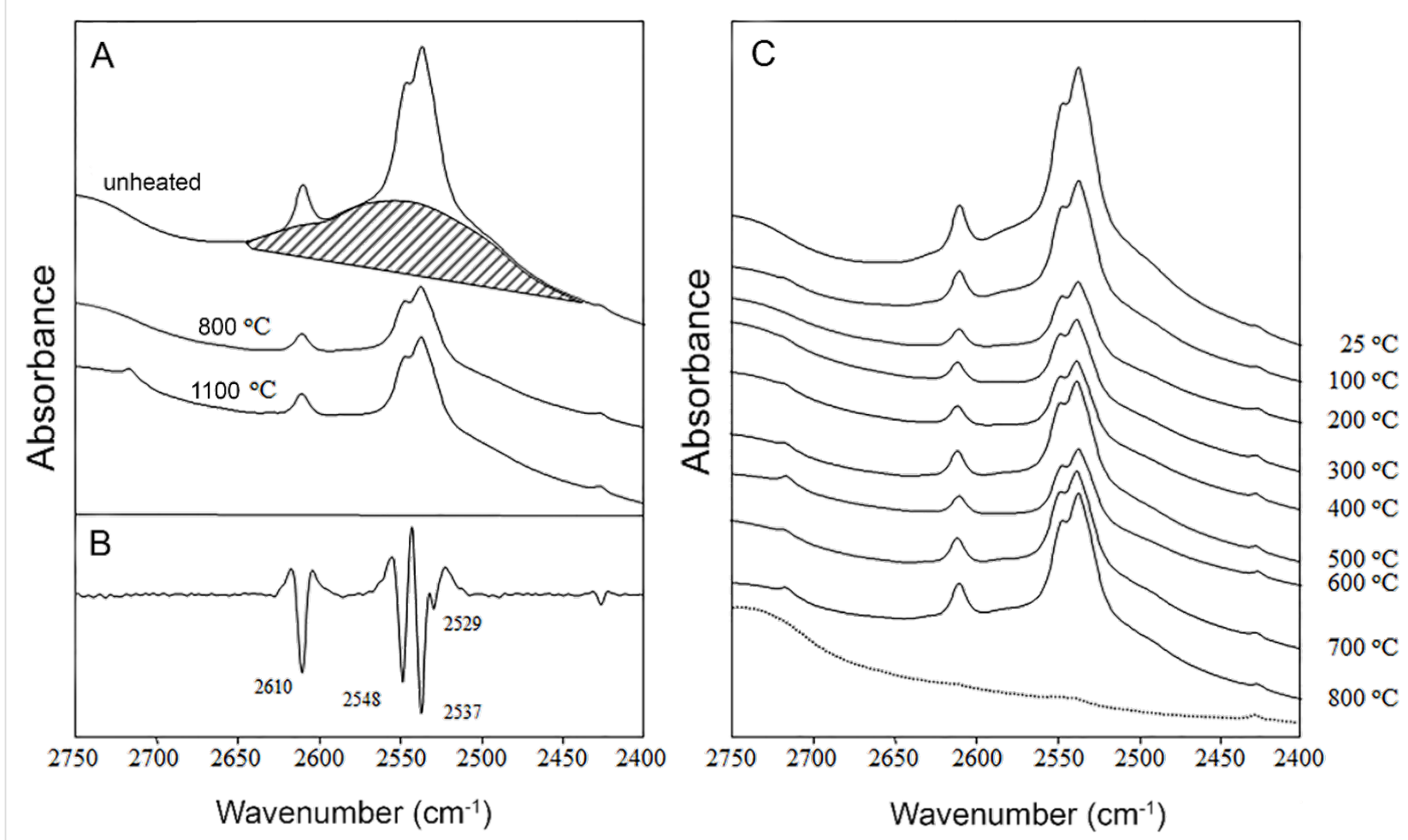

Figure 4: The -OD spectral band in $\mathrm{ZrO}_{2}$ samples synthesized in the presence of $\mathrm{D}_{2} \mathrm{O}$. (A) The stretching vibrations of the -OD groups in the $\mathrm{ZrO}$ samples synthesized in the presence of $\mathrm{D}_{2} \mathrm{O}$ and annealed at $800^{\circ} \mathrm{C}$ or $1100^{\circ} \mathrm{C}$. (B) The corresponding second derivative of the spectrum. (C) The temperature dependence of the $-\mathrm{OD}$ band. The dotted line represents the spectrum of $\mathrm{ZrO}_{2}$ powder obtained in the absence of $\mathrm{D}_{2} \mathrm{O}$, which therefore lacks -OD stretching vibrations.

$\mathrm{Zr}$ bonds. Therefore, contrary to conventional phase diagrams, the alternative to decomposition is not creation of molecules with saturated bonds, but rather, generation of broken bonds. This leads to the thermodynamic stability of the surface layers in contrast to bulk materials, where a phase transformation would occur under the given conditions [33].

$\mathrm{ZrO}_{2}$ samples were prepared in the presence of $\mathrm{D}_{2} \mathrm{O}$ and subsequently dried in vacuum at $25{ }^{\circ} \mathrm{C}$ or at $800{ }^{\circ} \mathrm{C}$, followed by immersion in $\mathrm{H}_{2} \mathrm{O}$ for $60 \mathrm{~min}$. A comparison of the FTIR spectra of the nano- $\mathrm{ZrO}_{2}$ before and after immersion in water (Figure 5) showed a simultaneous increase of the spectral absorption above $2700 \mathrm{~cm}^{-1}$ with an even larger $-\mathrm{OH}$ band at $3400 \mathrm{~cm}^{-1}$ (not shown), which gained intensity at the expense of $-\mathrm{OD}$. These data suggests that the -OD groups are on the surface and were readily exchangeable with - $\mathrm{OH}$ groups from water. It was observed that after immersion in water the signal from-OD disappears. This was observed for both the annealed and non-annealed sample. The disappearance of the -OD signal is evidence that the -OD groups were situated on the surface of the grains. Upon contact with water, the -OD groups on the grain surface were replaced by $-\mathrm{OH}$ from water. When the samples were dried and measured again, no -OD signal was detected. If the $\mathrm{D}^{+}$ions were situated in interior of the nanopar- ticle, they would not be replaced by $\mathrm{H}^{+}$, and the signal would not change. This experiment provides evidence that the ${ }^{-} \mathrm{OD}$ or ${ }^{-} \mathrm{OH}$ ions, which are situated on the NP surface, contribute to a reduction of the density of the nanoparticles.

\section{Nano- $\mathrm{ZrO}_{2}$ density in relation to specific surface area}

The FTIR results confirmed that the synthesis of zirconia under hydrothermal conditions produced nanopowders coated with a surface layer of $-\mathrm{OH}$ groups. Annealing the powders at temperatures up to $500{ }^{\circ} \mathrm{C}$ did not cause an increase in the crystallite size. Annealing at a temperature of $200{ }^{\circ} \mathrm{C}$ converted the amorphous material to crystalline, which was attributed to the evaporation of water adhered to the nanoparticles surface. The presence of clearly distinguishable peaks above that temperature indicates that the remaining hydroxy groups are for welldefined chemical bonds in the deeper layers of the zirconia NPs. An increase in the annealing temperature caused the crystallite diameter to increase to $72 \mathrm{~nm}$ (according to the Scherrer equation). The much larger apparent particle size indicated by the specific surface area measurements is the result of particle sintering. That is, the width of the XRD peaks depends on the size of the crystallites, while the specific surface area depends on the exposed surface of the sintered aggregates. During the 


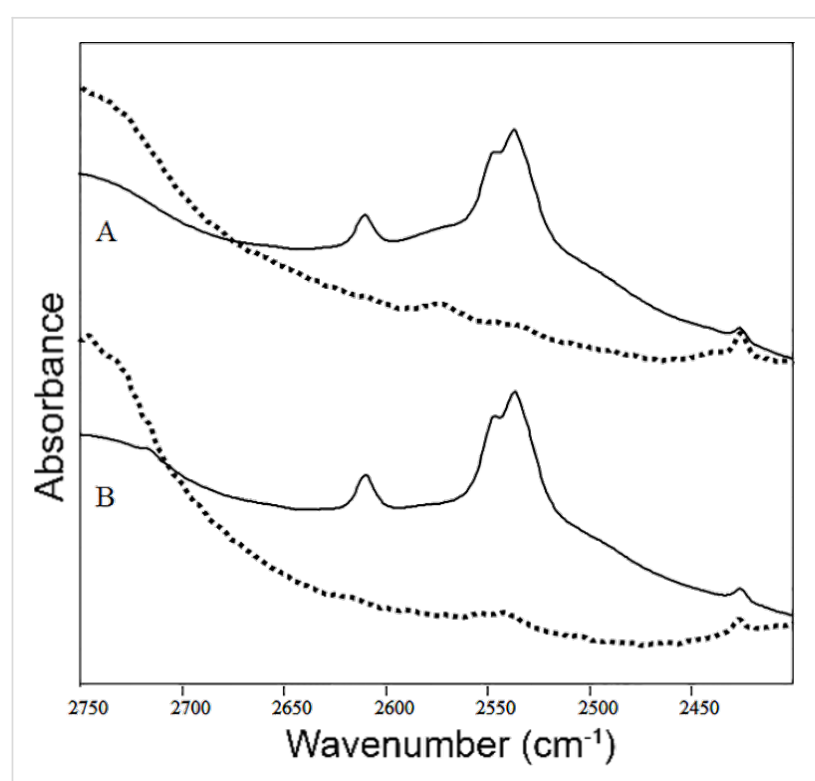

Figure 5: The infrared spectra of the $\mathrm{ZrO}_{2}$ samples prepared in the presence of $\mathrm{D}_{2} \mathrm{O}$ and subsequently dried in vacuum at $25^{\circ} \mathrm{C}(\mathrm{A})$ or at $800{ }^{\circ} \mathrm{C}(\mathrm{B})$. The dotted lines show the spectra after the samples were immersed for 60 min in $\mathrm{H}_{2} \mathrm{O}$, following the drying process.

sintering process, the $-\mathrm{OH}$ groups are most likely removed by evaporation of water, and the thus created dangling bonds are presumably saturated by creating chemical bonds between zirconium and oxygen atoms across the grain boundaries.

The results obtained for the $\mathrm{ZrO}_{2}$ nanopowder show a correlation between density and specific surface area (SSA, Figure 6A). It is clear that the greater the average grain size (and thus, the smaller the specific surface area), the greater the density. For very small particles of $11 \mathrm{~nm}$, the SSA is $97 \mathrm{~m}^{2} / \mathrm{g} \mathrm{ZrO}_{2}$. At the same time, the density of $\mathrm{ZrO}_{2}$ is low at
$5.22 \mathrm{~g} / \mathrm{cm}^{3}$ compared to $5.68 \mathrm{~g} / \mathrm{cm}^{3}$ for the monoclinic phase of bulk zirconia. Therefore, the growth of the particles causes an increase in the density (Figure 6A), making the density inversely proportional to the specific surface area. This observation is related to the presence of hydroxy groups on the nanomaterial surface. Similar behavior for bulk material was observed by Srdic et al. [34] who investigated the sintering process of nanocrystalline zirconia. The authors found that sintering at $950{ }^{\circ} \mathrm{C}$ under vacuum lead to an increase in particle size from $5 \mathrm{~nm}$ to $60 \mathrm{~nm}$ and an increase of the pellet density, which was attributed to a decrease of total surface of grain boundaries.

The experimental and calculated results of the density as a function of grain size for nano- $\mathrm{ZrO}_{2}$ are presented in Figure 6B. Assuming that the surface layer is $\mathrm{Zr}(\mathrm{OH})_{4}$, its thickness can be estimated by the fitting function of the effective density versus grain size. The following formula expresses the effective powder density as a function of core/shell densities, their thicknesses, and the grain size:

$$
\rho(x)=8 d^{3} \rho_{2}+12 d^{2} \rho_{2} x+6 d \rho_{2} x^{2}+\rho_{1} x^{3} /(2 d+x)^{3},(1)
$$

where $\rho_{1}$ is density of the core, $\rho_{2}$ is the density of the shell, $\mathrm{x}$ is diameter of the core, $d$ is the shell thickness, and $\rho$ is the effective (measured) density of the powder. Given the shell density, one can then calculate the shell thickness, $d$, in $\mathrm{nm}$.

Although the exact composition of the shell is not known, it can be assumed to be composed of hydrogen, oxygen and zirconium atoms. The molecules are bonded with one or two bonds to the nanoparticle surface and the surface layer chemical
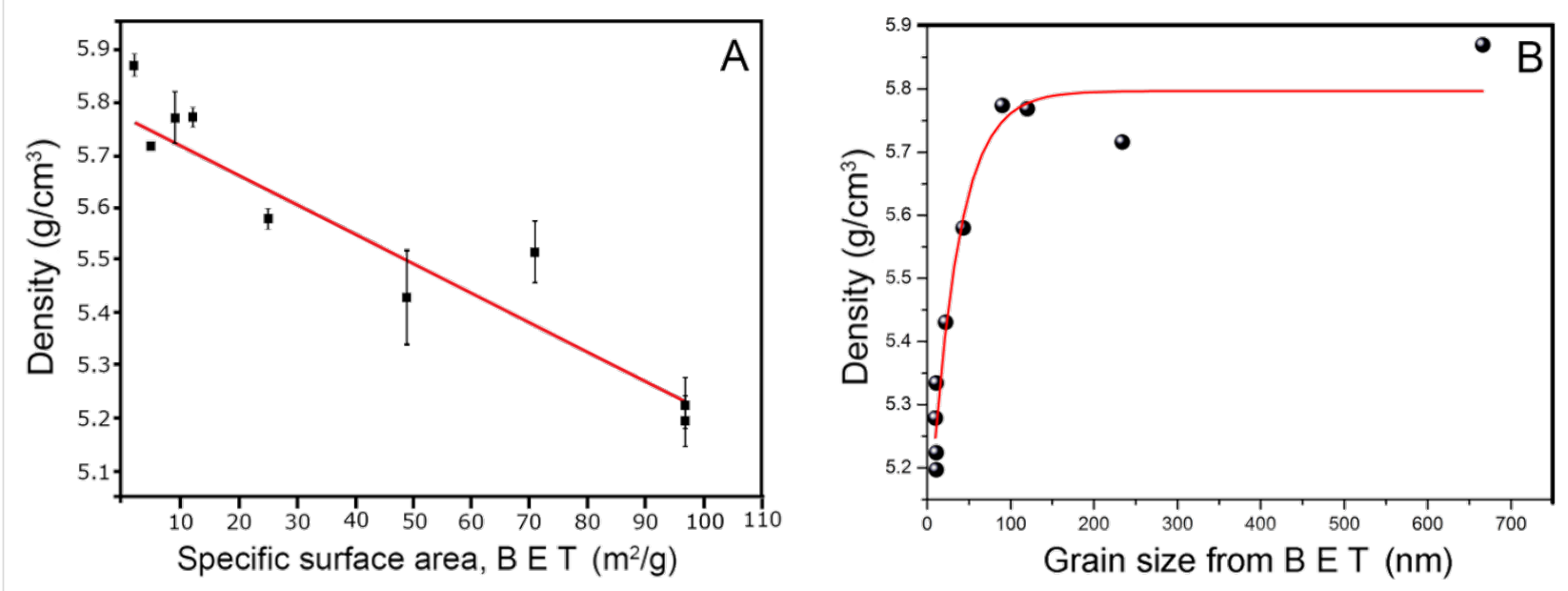

Figure 6: Density as a function of specific surface area (A), experimental and calculated correlation of density as a function of grain size from BET (B) for the nano- $\mathrm{ZrO}_{2}$. 
formula is perhaps $\mathrm{Zr}(\mathrm{OH})_{\mathrm{x}}$ with $\mathrm{x}<4$. Since the density of the layer was unknown, a composition of zirconia hydroxide $\mathrm{Zr}(\mathrm{OH})_{4}$ was assumed to further the discussion. According to [35], the density of zirconia hydroxide is $3.25 \mathrm{~g} / \mathrm{cm}^{3}$. Assuming this is the density of the shell, the fitting procedure results in $d=0.62 \pm 0.07 \mathrm{~nm}$. The diameter of the $\mathrm{Zr}(\mathrm{OH})_{4}$ molecule can be estimated to be $0.43 \mathrm{~nm}$. Thus, the thickness of the shell is of the same order of magnitude as the diameter of a zirconium hydroxide molecule. This result is in reasonable agreement with the idea of a monolayer of hydroxide bound to the nanoparticle surface, as observed during FTIR investigations. A surface shell with a slightly lower density than the bulk hydroxide (i.e., $2.80-3.0 \mathrm{~g} / \mathrm{cm}^{3}$ ) would result in an exact match of the theoretically calculated and the measured shell thickness. The density of the hydroxide shell layer could possibly be calculated using computer simulation methods.

This work presents a simple model to explain the correlation between the annealing temperature of nano- $\mathrm{ZrO}_{2}$ and its density (Figure 7). The density of nano- $\mathrm{ZrO}_{2}$ with a grain size of about $10 \mathrm{~nm}$ is $10 \%$ less than the theoretical value for this oxide.

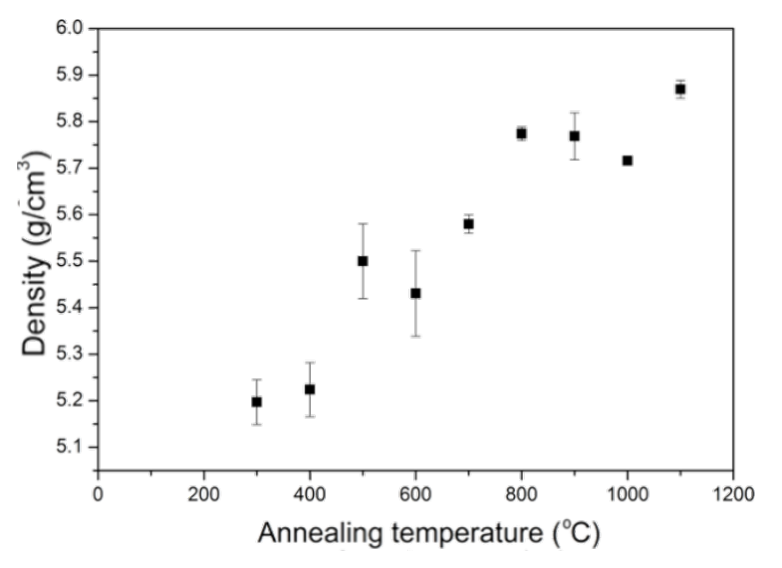

Figure 7: Density as a function of annealing temperature of nano- $\mathrm{ZrO}_{2}$ powder.

The density of the powder with grain size $100 \mathrm{~nm}$ is close to that of the single crystal. Thus, the variation of density with particle size is a classical nano effect, where new phenomena appear at particle sizes less than $100 \mathrm{~nm}$.

The results presented here are important for nanoparticle metrology and determination of their quality. The smaller the grain size, the larger the contribution of the low density surface layer to the average density. The technological aim is usually to obtain particles with an inconspicuous surface layer, for instance, capped with as few -OH groups as possible. A lowdensity layer covering the surface of the nanosized particles will lead to a decrease of average density, and this decrease will be more important for small particles as compared to large ones. Ideally, high quality nanoparticles should be situated in the upper right corner of the SSA vs density plot of in Figure 6A, giving the maximum possible density for a given specific surface area.

\section{Conclusion}

It was found that the density of nanoparticles decreases as their size decreases, or as the specific surface area increases. This effect is caused by the surface layer contribution to the average density of the nanoparticles. A surface layer of hydroxy groups is present on the surface of nano- $\mathrm{ZrO}_{2}$ particles produced using a hydrothermal process. Many of the hydroxy groups disappear after annealing at $400{ }^{\circ} \mathrm{C}$, however a layer of adsorbed hydroxide remains stable even after heating to $1100{ }^{\circ} \mathrm{C}$ and contributes to a reduction in the NP density. It was found that the influence of the surface layer on the NPs density becomes particularly visible for nanoparticles smaller than $50 \mathrm{~nm}$.

The technique of heavy water substitution allowed evaluation of changes in the zirconia surface layers as a function of the processing parameters by using FTIR without the need of in situ measurements in a vacuum chamber. The FTIR spectra of the -OD groups after annealing up to $1100{ }^{\circ} \mathrm{C}$ indicate a highly ordered structure of the surface layer with four well-defined and distinct types of -OD molecular bonding. Additionally, the -OD groups located on the surface readily exchange with the $-\mathrm{OH}$ groups in the water.

The correlation between density and specific surface area of the nanopowder can be useful for the characterization of nanomaterials and for assessment of their quality. In many cases the technological goal is to avoid amorphous layers and obtain fully crystalline nanoparticles with high density. Nevertheless, because of the surface layers, for a given average NP diameter, a maximum density can be achieved, which is less than for bulk materials.

\section{Experimental}

Nanocrystalline zirconia powders were produced using a microwave-driven hydrothermal process performed at up to 5.5 MPa for $20 \mathrm{~min}$ using a previously described procedure [22]. The present synthesis procedure for $\mathrm{ZrO}_{2}$ was modified by the substitution of a 50/50 mixture of water $\left(\mathrm{H}_{2} \mathrm{O}\right)$ and heavy water $\left(\mathrm{D}_{2} \mathrm{O}\right)$ as the synthesis medium. The solution of $\mathrm{ZrOCl}_{2} \cdot 8 \mathrm{H}_{2} \mathrm{O}(0.5 \mathrm{M})$ was adjusted to $\mathrm{pH} 10$ with $\mathrm{NaOH}(1 \mathrm{M})$ and poured into a Teflon reaction vessel in the microwave reactor. The microwave reactor ("ERTEC", Wroclaw, Poland), was operated at $2.45 \mathrm{GHz}$, and permitted hydrothermal synthesis at pressures up to $10 \mathrm{MPa}$. After the reaction was 
complete, the solid phase was filtered from the solution and washed free of dissolved salts with distilled water. The filtered powders were air dried and then annealed in air at temperatures ranging from 25 to $1100{ }^{\circ} \mathrm{C}$ for $30 \mathrm{~min}$. Two selected powders, one dried at $25^{\circ} \mathrm{C}$ and one annealed at $800{ }^{\circ} \mathrm{C}$, were rinsed for $60 \mathrm{~min}$ in $\mathrm{H}_{2} \mathrm{O}$ in order to remove - $\mathrm{OD}$ groups, as explained below.

To assess the type and amount of surface layers in the nanoparticles, $\mathrm{KBr}$-based pellets containing $1 \mathrm{wt} \% \mathrm{ZrO}_{2}$ were prepared for FTIR spectral analysis. FTIR commonly shows a strong infrared absorption around $3400 \mathrm{~cm}^{-1}$ that corresponds to stretching vibrations of the $-\mathrm{OH}$ bonds. Studies of the annealing effect on $-\mathrm{OH}$ groups on the nanoparticle surfaces are typically carried out in vacuum $[19,27]$ since water vapor and $-\mathrm{OH}$ groups attached to the surface during synthesis or thermal treatment cannot be distinguished from hydroxy groups formed when the samples are transported in air to the spectrometer. However, the -OD groups observed during our FTIR studies were incorporated into the nanoparticles during synthesis, thus a vacuum system was unnecessary. The -OD stretching vibrations are manifested as a separate band in the infrared spectrum $\left(2600-2400 \mathrm{~cm}^{-1}\right)$. This band does not overlap with other infrared peaks and its intensity can be conveniently used as an estimation for the concentration of surface hydroxid groups.

All FTIR spectra were collected in transmission mode using a Nicolet NEXUS FTIR spectrometer equipped with a liquid nitrogen-cooled MCT detector. Each spectrum was the sum of 128 interferograms, with a resolution of $4 \mathrm{~cm}^{-1}$. The sample chamber was continuously purged with dry, $\mathrm{CO}_{2}$-free air. All data processing, including the calculation of the second derivative Savitzky-Golay spectra, was performed using OMNIC and GRAMS software by Nicolet and ThermoNicolet, respectively.

The determination of the surface area of the powders was carried out using the BET method with a Micromeritics Instruments Gemini 2360 apparatus with nitrogen as the adsorbate. The particle size was calculated based on the BET data, assuming spherical particles, using:

$$
\Phi=\sigma S^{-1} \rho^{-1},
$$

Where $\sigma$ is the average particle diameter, $S$ is the specific surface area of the powder and $\rho$ is the density of zirconia.

The powders were analyzed with an X-ray diffractometer ( $\mathrm{Cu} \mathrm{K \alpha}$, Siemens Model D5000). The X-ray diffraction patterns were collected in a $2 \theta$ range of $20-90^{\circ}$ at room temperature, with a step increment of $0.05^{\circ}$. The Scherrer equation was used to calculate the average crystallite diameter [36].

As previously described [22], the density of the powders was measured using helium pycnometry (Model AccuPyc 1330, Micromeritics Instruments). The in-house procedure for the density measurement was as follows: the powders were flushed in a helium atmosphere for $120 \mathrm{~min}$ at $220^{\circ} \mathrm{C}$, weighed, and then transferred to the helium pycnometer. The nanoparticle density can be influenced by air absorbed onto the surface of the nanopowder during transfer to the pycnometer. Therefore, the measurement was repeated up to 100 times, and the density as a function of the number of cycles was plotted. Each cycle partially removed the absorbed water and the density increased. The process was stopped when the results reached an asymptotic value, and this value was taken as the powder density.

The morphology of the powders was examined using a LEO 1530 Scanning Electron Microscope.

\section{Acknowledgments}

This study was conducted at the Institute of High Pressure Physics, Polish Academy of Science (PAS) and was supported by the project NanoForce - Nanotechnology for Chemical Enterprises "How to link scientific knowledge to the business in the Central Europe space", implemented through the Central Europe Programme, and co-financed by the ERDF (http:// www.nanoforceproject.eu). The authors are grateful to Dr. Roman Pielaszek for help with the fitting procedures.

\section{References}

1. Cao, Z.; Zhang, Z. Appl. Surf. Sci. 2011, 257, 4151-4158. doi:10.1016/j.apsusc.2010.11.188

2. Haw, J. F.; Nicholas, J. B.; Song, W.; Deng, F.; Wang, Z.; Xu, T.; Heneghan, C. S. J. Am. Chem. Soc. 2000, 122, 4763-4775. doi:10.1021/ja994103x

3. Navío, J. A.; Hidalgo, M. C.; Colon, G.; Botta, S. G.; Litter, M. I. Langmuir 2001, 17, 202-210. doi:10.1021/la000897d

4. Santos, C.; Souza, R. C.; Almeida, N.; Almeida, F. A.; Silva, R. R. F.; Fernandes, M. H. F. V. J. Mater. Process. Technol. 2008, 200, 126-132. doi:10.1016/j.jmatprotec.2007.08.061

5. Zheng, W.-T.; Sun, K.-Q.; Liu, H.-M.; Liang, Y.; Xu, B.-Q. Int. J. Hydrogen Energy 2012, 37, 11735-11747. doi:10.1016/j.ijhydene.2012.05.099

6. Xi, J.; Tang, X. Chem. Phys. Lett. 2004, 393, 271-276. doi:10.1016/j.cplett.2004.06.054

7. Sun, Z.; Zhang, X.; Na, N.; Liu, Z.; Han, B.; An, G. J. Phys. Chem. B 2006, 110, 13410-13414. doi:10.1021/jp0616359

8. Benfer, S.; Knozinger, E. J. Mater. Chem. 1999, 9, 1203-1209. doi:10.1039/a809164a

9. Woodley, S. M.; Hamad, S.; Mejíasb, J. A.; Catlow, C. R. A. J. Mater. Chem. 2006, 16, 1927-1933. doi:10.1039/b600662k 
10. Wu, Y.; Bandyopadhyay, A.; Bose, S. Mater. Sci. Eng., A 2004, 380, 349-355. doi:10.1016/j.msea.2004.04.036

11. Bertrand, G.; Mévrel, R. Thin Solid Films 1997, 292, 241-246. doi:10.1016/S0040-6090(96)09099-2

12. Ehrhart, G.; Bouazaoui, M.; Capoen, B.; Ferreiro, V.; Mahiou, R.; Robbe, O.; Turrell, S. Opt. Mater. 2007, 29, 1723-1730. doi:10.1016/j.optmat.2006.09.006

13. Patra, A.; Friend, C. S.; Kapoor, R.; Prasad, P. N. Appl. Phys. Lett. 2003, 83, 284-287. doi:10.1063/1.1592891

14. Reisfeld, R.; Zelner, M.; Patra, A. J. Alloys Compd. 2000, 300-301, 147-151. doi:10.1016/S0925-8388(99)00714-8

15. Urlacher, C.; de Lucas, C. M.; Mugnier, J. Synth. Met. 1997, 90, 199-204. doi:10.1016/S0379-6779(98)80007-6

16. Urlacher, C.; de Lucas, C. M.; Bernstein, E.; Jacquier, B.; Mugnier, J. Opt. Mater. 1999, 12, 19-25. doi:10.1016/S0925-3467(98)00051-2

17. Millers, D.; Grigorjeva, L.; Opalińska, A.; Łojkowski, W. Solid State Phenom. 2003, 94, 135-140. doi:10.4028/www.scientific.net/SSP.94.135

18. Leroy, C. M.; Cardinal, T.; Jubera, V.; Aymonier, C.; Treguer-Delapierre, M.; Boissière, C.; Grosso, D.; Sanchez, C.; Viana, B.; Pellé, F. Microporous Mesoporous Mater. 2013, 170, 123-130. doi:10.1016/j.micromeso.2012.11.014

19. Aillon, K. L.; Xie, Y.; El-Gendy, N.; Berkland, C. J.; Forrest, M. L. Adv. Drug Delivery Rev. 2009, 61, 457-466. doi:10.1016/j.addr.2009.03.010

20. Powers, K. W.; Brown, S. C.; Krishna, V. B.; Wasdo, S. C.; Moudgil, B. M.; Roberts, S. M. Toxicol. Sci. 2006, 90, 296-303. doi:10.1093/toxsci/kfj099

21. Bohé, A. E.; Andrade-Gamboa, J.; Pasquevich, D. M.; Tolley, A. J.; Pelegrina, J. L. J. Am. Ceram. Soc. 2000, 83, 755-760. doi:10.1111/j.1151-2916.2000.tb01270.x

22. Opalinska, A.; Leonelli, C.; Lojkowski, W.; Pielaszek, R.; Grzanka, E.; Chudoba, T.; Matysiak, H.; Wejrzanowski, T.; Kurzydlowski, K. J. J. Nanomater. 2006, 2006, 98769-98777. doi:10.1155/JNM/2006/98769

23. Takeda, S.; Fukawa, M.; Hayashi, Y.; Matsumoto, K. Thin Solid Films 1999, 339, 220-224. doi:10.1016/S0040-6090(98)01152-3

24. Graeve, O. A.; Varma, S.; Rojas-George, G.; Brown, D. R.; Lopez, E. A. J. Am. Ceram. Soc. 2006, 89, 926-931. doi:10.1111/j.1551-2916.2006.00845.x

25. Takeda, S.; Fukawa, M. Thin Solid Films 2003, 444, 153-157. doi:10.1016/S0040-6090(03)01094-0

26. Takeda, S.; Fukawa, M. Mater. Sci. Eng., B 2005, 119, 265-267. doi:10.1016/j.mseb.2004.12.078

27. Tamura, H.; Tanaka, A.; Mitia, K.-y.; Furuichi, R. J. Colloid Interface Sci. 1999, 209, 225-231. doi:10.1006/jcis.1998.5877

28. Tamura, H.; Mita, K.; Tanaka, A.; Ito, M. J. Colloid Interface Sci. 2001, 243, 202-207. doi:10.1006/jcis.2001.7864

29. Jiao, X.; Chen, D.; Xiao, L. J. Cryst. Growth 2003, 258, 158-162. doi:10.1016/S0022-0248(03)01473-8

30. Kolen'ko, Y. V.; Maksimov, V. D.; Garshev, A. V.; Mukhanov, V. A.; Oleynikov, N. N.; Churagulov, B. R. Russ. J. Inorg. Chem. 2004, 49, 1133-1137.

31. Maglia, F.; Tredici, I. G.; Anselmi-Tamburini, U. J. Eur. Ceram. Soc. 2013, 33, 1045-1066. doi:10.1016/j.jeurceramsoc.2012.12.004

32. Ray, J. C.; Pati, R. K.; Pramanik, P. J. Eur. Ceram. Soc. 2000, 20 , 1289-1295. doi:10.1016/S0955-2219(99)00293-9

33. Łojkowski, W.; Fecht, H.-J. Prog. Mater. Sci. 2000, 45, 339-568. doi:10.1016/S0079-6425(99)00008-0
34. Srdić, V. V.; Winterer, M.; Hahn, H. J. Am. Ceram. Soc. 2000, 83, 729-736. doi:10.1111/j.1151-2916.2000.tb01266.x

35. "ChemBlink, Online Database of Chemicals from Around the World". http://www.chemblink.com/index.htm (accessed Nov 7, 2014).

36. Patterson, A. L. Phys. Rev. 1939, 56, 978-982. doi:10.1103/PhysRev.56.978

\section{License and Terms}

This is an Open Access article under the terms of the Creative Commons Attribution License

(http://creativecommons.org/licenses/by/2.0), which permits unrestricted use, distribution, and reproduction in any medium, provided the original work is properly cited.

The license is subject to the Beilstein Journal of Nanotechnology terms and conditions:

(http://www.beilstein-journals.org/bjnano)

The definitive version of this article is the electronic one which can be found at: doi:10.3762/bjnano.6.4 